\title{
PERBANDINGAN PUPASI DUA JENIS KUPU-KUPU Troides helena DAN Pachliopta aristolochiae (LEPIDOPTERA: PAPILIONIDAE)
}

\author{
PUPATION COMPARISON OF Troides helena AND \\ Pachliopta aristolochiae (LEPIDOPTERA: PAPILIONIDAE)
}

\author{
Emilia Apriyanti ${ }^{1 \star}$, Herawati Soekardi ${ }^{1}$, Nismah Nukmal ${ }^{1}$ \\ 1Jurusan Biologi, FMIPA Universitas Lampung \\ *emiliaap50@gmail.com
}

\begin{abstract}
ABSTRAK
T. helena dan $P$. aristolochiae merupakan spesies kupu-kupu yang memakan tanaman pakan yang sama (Aristolochia tagala) pada fase larva. Ketika akan memasuki fase pupa, larva kupu-kupu $T$. helena dan $P$. aristolochiae mengalami pupasi yang diawali dengan aktifnya hormon prothoracicotropic (PTTH) yang memicu larva untuk berhenti makan. Penelitian ini bertujuan untuk membandingkan tahapan dan waktu yang dibutuhkan dari awal pupasi hingga terbentuk pupa dari dua jenis kupu-kupu. Penelitian dilakukan pada bulan Januari 2016 di Taman Kupu-kupu Gita Persada Lampung. Sepuluh larva instar terakhir $T$. helena dan $P$. aristolochiae hasil penangkaran diamati aktivitasnya setiap satu jam hingga terbentuk pupa, serta pengukuran panjang benang dan penimbangan berat pupa. Data yang diperoleh dianalisis secara deskriptif, uji t (Independent Sample Test), dan analisis korelasi untuk panjang benang dan berat pupa. Hasil menunjukkan bahwa pada awal memasuki pupasi, larva instar terakhir $T$. helena dan $P$. aristolochiae memiliki aktivitas yang sama, yaitu berhenti makan dan mencari tempat yang cocok yang akan digunakan sebagai tempat menggantung. Larva memendekkan tubuhnya, membuat benang, menggantung dan kemudian membentuk pupa. Pembuatan benang $T$. helena dan $P$. aristolochiae terjadi pada malam hari. Hasil analisis uji t menunjukkan bahwa rata-rata lama pupasi kupu-kupu T. helena dan $P$. aristolochiae berbeda nyata $(\rho<0,03)$, ratarata pupasi $T$. helena 4,8 jam lebih lama dibandingkan $P$. aristolochiae. Adanya korelasi positif antara panjang benang dan berat dengan nilai $r T$. helena : 0,94 dan $r P$. aristolochiae : 0,60
\end{abstract}

Kata Kunci : T. helena, P. aristolochiae, pupasi

\section{ABSTRACT}

Larval stages of both $T$. helena and $P$. aristolochiae feed on the same plant (Aristolochia tagala). T. helena and P. aristolochiae larvaes would be through the pupation before entering the pupa stage. The pupation should be started with prothoracicotropic hormone (PTTH) activation, that trigger larvaes to stop eating. The purpose of the research to compare the pupation stages and times needed from the beginning pupation until the pupa formed. The research was done on January 2016 in Gita Persada Butterfly Park Lampung. Ten of last instar larvaes of T. helena and P. aristolochiae from captivity crops were observed their activities every one hour until the pupa formed. Length of silk and pupa weight were measured. The obtained datas were analyzed descriptively, using t-test (Independent Sample Test) and correlation analysis for silk's length and pupa's weight. The result showed that at entering of pupation, the latest instar larvaes of $T$. helena and P. aristolochiae had the same activity, such as stopped eating and searched the suitable places for hang up. After that, the larvaes shorten their body, constructed the silk, hanged up, and formated to a the pupa respectively. The silk construction of $T$. helena and $P$. aristolochiae occurred at the night. The result showed that the mean duration of pupation of $T$. helena and $P$. aristolochiae had significantly different $(\rho<0,03)$, the duration mean pupation of $T$. helena 4.8 hours longer than pupation of $P$. aristolochiae. There have positive correlation between silk length and pupa weight with the value of $r$ T. helena : 0,94 and $r$ $P$. aristolochiae : 0,60

Keyword: T. helena, P. aristolochiae, pupation 


\section{PENDAHULUAN}

Papilionidae merupakan salah satu famili yang termasuk dalam sub ordo Rophalocera yang mempunyai spesies yang beraneka ragam. Papilionidae disebut dengan swallowtail karena sebagian besar anggotanya mempunyai ekor yang muncul dari vena keempat sayap belakang dan vena protocol (Salmah et al., 2002). Famili Papilionidae diperkirakan mempunyai anggota sebanyak 700 spesies yang tersebar diseluruh dunia (Smart, 1991), 19 spesies diantaranya terdapat di Taman Kupu-kupu Gita Persada (Martinus, 2015).

Spesies yang termasuk anggota famili Papilionidae antara lain adalah Troides helena dan Pachliopta aristolochiae. Kedua spesies tersebut memakan Aristolochia tagala pada fase larva (Soekardi, 2005; Chin, 2014). T. helena merupakan salah satu spesies yang masuk dalam daftar Appendix II CITES sejak tahun 1979 (Soehartono \& Mardiastuti, 2003), sedangkan $P$. aristolochiae menurut IUCN dikategorikan sebagai jenis kupu- kupu yang tidak terancam karena populasinya yang masih banyak di alam (IUCN, 2015).

T. helena dan P. aristolochiae mengalami siklus hidup seperti kupu-kupu pada umumnya, yaitu dimulai dari fase telur, larva, pupa, dan imago. Sebelum memasuki fase pupa, larva instar terakhir akan mengalami pupasi yang diawali dengan aktifnya hormon prothoracicotropic (PTTH) yang memicu larva untuk berhenti makan. Larva instar terakhir yang telah mencapai pertumbuhan maksimal akan mencari tempat yang cocok untuk pupasi, tempat tersebut dapat berupa tanaman inang, tanaman lain yang ada didekatnya, daun kering, atau tempat yang dapat digunakan sebagai tempat berlindung (Regina, 2008). Lama pupasi setiap spesies kupu-kupu berbeda, lama pupasi ini sangat dipengaruhi oleh faktor biotik dan abiotik (Guillott, 2005).

Penelitian mengenai siklus hidup kupu-kupu $T$. helena dan $P$. aristolochiae sudah banyak dilakukan, namun informasi mengenai pupasi kupu-kupu $T$. helena dan $P$. aristolochiae masih sangat terbatas. Untuk itu penelitian ini sangat diperlukan agar dapat memberi informasi mengenai tahapan-tahapan yang terjadi serta waktu yang dibutuhkan dari awal pupasi hingga terbentuk pupa $T$. helena dan $P$. aristolochiae.

\section{BAHAN DAN METODE}

Penelitian ini dilaksanakan di Taman Kupukupu Gita Persada Lampung pada bulan Januari 2016. Alat dan bahan yang digunakan dalam penelitian ini adalah kotak penangkaran, tanaman pakan larva (Arisolochia tagala), kertas label, penggaris dan timbangan digital.

Hewan uji yang digunakan masing-masing 10 ekor larva instar terakhir T. helena dan $P$. aristolochiae, diperoleh dengan cara penangkaran. Pengamatan pupasi dilakukan dengan metode observasi setiap satu jam sekali dengan mencatat aktivitas aktivitas yang terjadi dimulai dari awal pupasi hingga menjadi pupa. Panjang benang pupa $T$. helena dan $P$. aristolochiae diukur menggunakan penggaris, sedangkan 
berat pupa ditimbang menggunakan timbangan digital. Data yang diperoleh terdiri dari waktu pembuatan benang saat pupasi, dan rata-rata lama pupasi kupukupu $T$. helena dan $P$. aristolochiae dianalisis secara deskriptif dan uji $t$ (Independent Sample Test) pada taraf uji $5 \%$ dan untuk mengetahui hubungan antara panjang benang dan berat pupa dianalisis dengan korelasi.

\section{HASIL DAN PEMBAHASAN}

Berdasarkan hasil penelitian yang telah dilakukan, larva $T$. helena dan $P$. aristolochiae ketika memasuki pupasi menunjukkan aktivitas yang hampir sama. Larva yang memasuki pupasi berhenti makan dan berjalan mencari tempat yang cocok, misalnya pada ranting atau dinding kotak penangkaran. Larva diam dan tubuhnya memendek, selanjutnya larva akan membuat benang yang berasal dari kelenjar saliva yang berfungsi untuk menggantungkan tubuhnya. Aktivitas pupasi dapat dilihat pada Gambar 1.

Pada larva $T$. helena dan $P$. aristolochiae, benang dibuat pada bagian posterior dan anterior larva. Ketika membuat benang pada bagian anterior, larva akan membalikkan tubuhnya 180 derajat. Hal ini sesuai dengan hasil penelitian Barua \& Slowik (2007) yang menyatakan larva $P$. aristolochiae diam kemudian secara lambat membalikan ujung posterior tubuhnya dan mengeluarkan benang-benang hitam dan merekatkannya pada batang. Selanjutnya larva membalikan kembali tubuhnya dan membuat benang-benang pada bagian anterior.

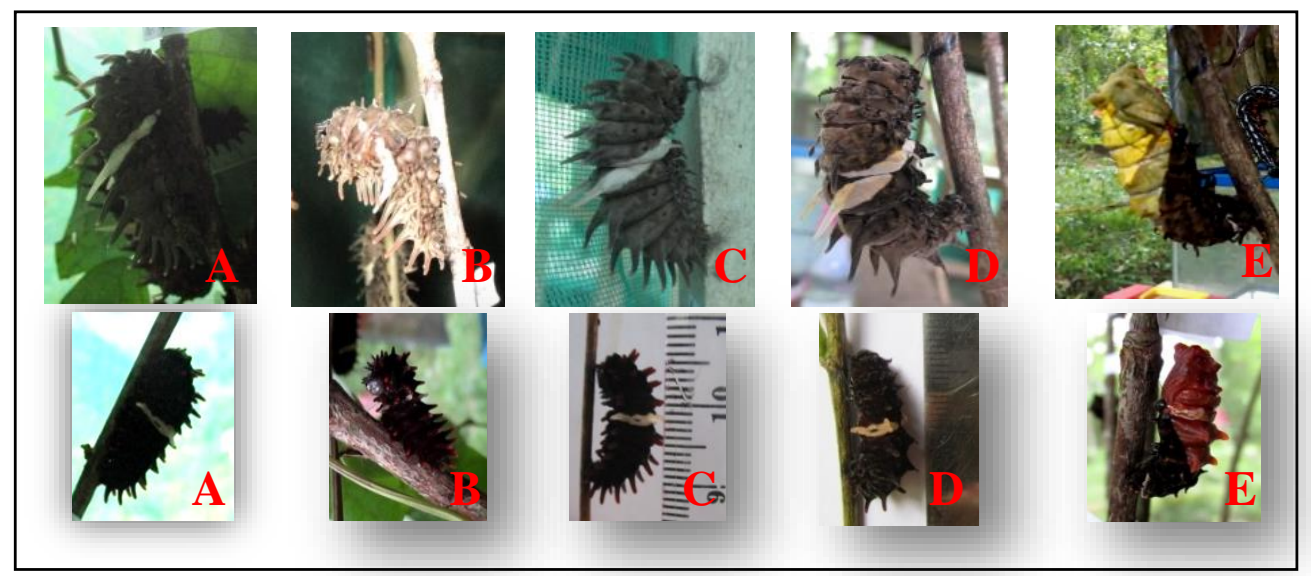

Gambar 1. Aktivitas pupasi T. helena (atas) dan P. aristolochiae (bawah), A). larva memendek, B). membuat benang, C). melengkung dan menggantung, D) warna larva pucat dan kulit melunak, E). kulit larva terlepas.

Pada penelitian ini diketahui bahwa larva $T$.

helena dan $P$. aristolochiae membuat

benang pada malam hari seperti yang

terlihat pada Tabel 1. Larva T. helena 100

$\%$ membuat benang pada malam hari

sedangkan larva $P$. aristolochiae $80 \%$

membuat benang di malam hari dan $20 \%$ pada siang hari. Penelitian mengenai waktu pembuatan benang pada masa pupasi belum pernah dilakukan, sehingga hasil penelitian mengenai pembuatan benang ini dapat dikatakan sebagai data hasil penelitian baru (new record). 
Tabel 1. Waktu pembuatan benang pada larva $T$. helena dan $P$. aristolochiae.

\begin{tabular}{ccc}
\hline $\begin{array}{c}\text { Spesies } \\
\mathrm{n}(10)\end{array}$ & Siang & Malam \\
\hline T. helena & 0 & 10 \\
& $(0 \%)$ & $(100 \%)$ \\
P. aristolochiae & 2 & 8 \\
& $(20 \%)$ & $(80 \%)$ \\
\hline
\end{tabular}

Keterangan: Siang pada pukul 08.30-13.30, dan malam pada pukul $19.30-02.30$

Larva yang selesai membuat benang akan melengkung dan menggantungkan tubuhnya. Ketika masa pupasi akan selesai, larva menjadi berwarna pucat dan kulitnya melunak. Kulit larva pecah dibagian dorsal, larva mengoyangkan tubuhnya kekiri dan kekanan, lalu kulit larva terlepas dan terbentuklah pupa. Pupa yang baru terbentuk dalam keadaan basah dan akan mulai mengering setelah satu jam.
Soekardi (2007) menyatakan bahwa pada fase awal pupa, kulit pupa lunak dan kemudian akan menjadi keras.

Hasil analisis uji t (Independent Samples Test) menggunakan SPSS 16 for windows pada aktivitas fase pupasi kupu-kupu $T$. helena dan $P$. aristolochiae menunjukkan bahwa rata-rata lama pupasi dari mencari tempat hingga menggantung $T$. helena tidak berbeda nyata dengan $P$. aristolochiae $(\boldsymbol{\rho}=0,80)$, sedangkan rata-rata waktu dari menggantung hingga terbentuk pupa sangat berbeda nyata $(\boldsymbol{\rho}<0,001)$. Ratarata waktu pupasi $T$. helena 4,80 jam lebih lama dari $P$. aristolochiae (Tabel 2). Menurut Larasati (2015), lama pupasi $T$. helena yaitu 1 hari, sedangkan lama pupasi P. aristolochiae yaitu 14-15 jam (Bashar et al., 2014).

Tabel 2. Rata-rata lama (jam $\pm \mathrm{sd}$ ) pupasi kupu-kupu T. helena dan $P$. aristolochiae

\begin{tabular}{lcccc}
\hline \multicolumn{1}{c}{$\begin{array}{c}\text { Spesies } \\
(\mathbf{n = 1 0})\end{array}$} & $\begin{array}{c}\text { Mencari tempat - } \\
\text { membuat } \\
\text { benang }\end{array}$ & $\begin{array}{c}\text { Membuat } \\
\text { benang - } \\
\text { menggantung }\end{array}$ & $\begin{array}{c}\text { Menggantung - } \\
\text { terbentuk pupa }\end{array}$ & Lama pupasi \\
\hline T. helena & $8,60 \pm 3,03 \mathrm{a}$ & $6,50 \pm 2,37 \mathrm{a}$ & $34,00 \pm 1,25 \mathrm{a}$ & $49,10 \pm 3,78 \mathrm{a}$ \\
P. aristolochiae & $8,30 \pm 2,36 \mathrm{a}$ & $6,70 \pm 1,16 \mathrm{a}$ & $29,30 \pm 1,77 \mathrm{~b}$ & $44,30 \pm 2,26 \mathrm{~b}$ \\
\hline
\end{tabular}

Keterangan: Angka yang diikuti oleh huruf yang sama pada kolom yang sama tidak berbeda nyata pada uji-t dengan taraf signifikasi $5 \%$

Penggukuran terhadap panjang benang dan berat pupa juga dilakukan untuk mengetahui korelasi antara keduanya. Panjang benang $T$. helena dua kali lebih panjang dibandingkan dengan panjang benang $P$. aristolochiae, hal ini disebabkan karena ukuran pupa $T$. helena lebih besar dibandingkan ukuran pupa $P$. aristolochiae. Ukuran pupa yang besar membutuhkan benang yang lebih panjang sehingga mampu menopang berat pupa untuk menggantung. Hasil pengukuran panjang benang dan berat pupa dapat dilihat pada Tabel 3.

Tabel 3. Ukuran panjang benang ( $\mathrm{cm} \pm \mathrm{sd}$ ) dan berat pupa $(g \pm s d)$

\begin{tabular}{ccc}
\hline $\begin{array}{c}\text { Pupa } \\
(\mathbf{n = 1 0})\end{array}$ & Berat & $\begin{array}{c}\text { Panjang } \\
\text { benang }\end{array}$ \\
\hline T.helena & $4,81 \pm 1,39^{\mathrm{a}}$ & $1,94 \pm 0,17^{\mathrm{a}}$ \\
P.aristolochiae & $0,98 \pm 1,91^{\mathrm{b}}$ & $0,95 \pm 0,14^{\mathrm{b}}$ \\
\hline Keterangan: Angka yang diikuti oleh huruf \\
yang sama pada kolom yang \\
sama tidak berbeda nyata \\
pada uji-t dengan taraf \\
signifikasi $5 \%$
\end{tabular}


Hasil analisis korelasi antara panjang benang dan berat pupa menunjukkan bahwa ada korelasi positif yang sangat kuat antara panjang benang dan berat pupa $T$. helena dengan nilai $r=0,94, \rho<0,001$, sedangkan pupa $P$. aristolochiae menunjukkan korelasi positif yang kuat dengan $r=0,60, \boldsymbol{\rho}=0,31$ (Irianto, 2006). Korelasi antara panjang benang dan berat pupa $T$. helena dan $P$. aristolochiae dapat dilihat pada Gambar 2.

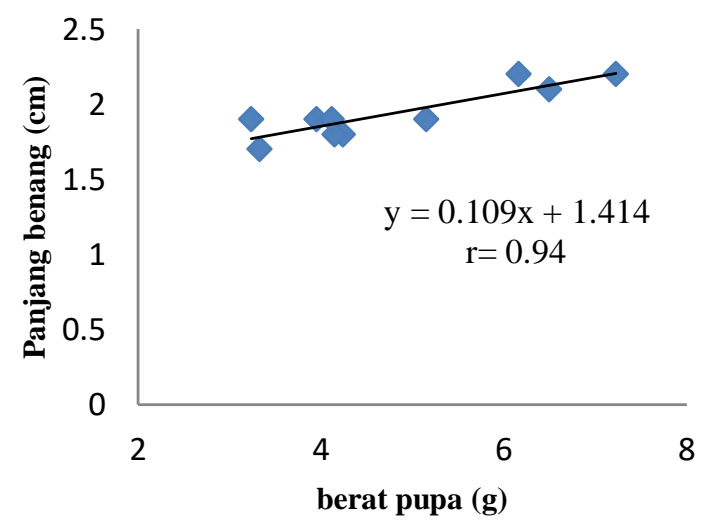

(a)

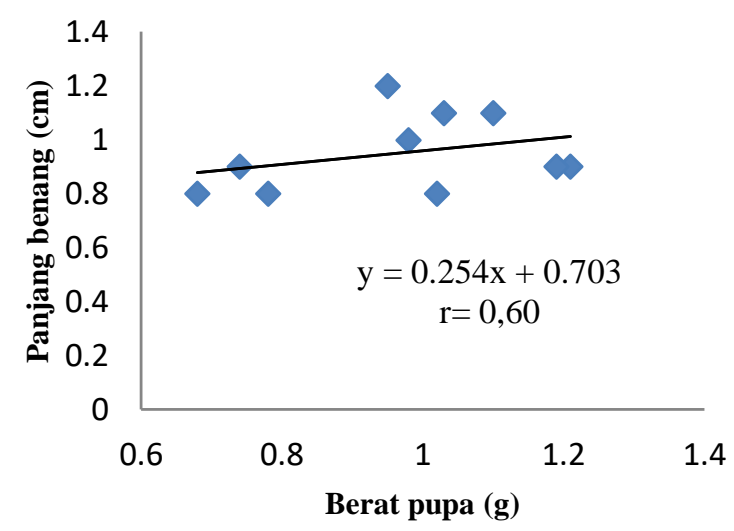

(b)

Gambar 2. Korelasi panjang benang dan berat pupa $T$. helena (a) dan $P$. aristolochiae (b)

\section{KESIMPULAN}

Kesimpulan yang dapat diambil dari penelitian ini adalah aktivitas dari awal pupasi hingga terbentuk pupa $T$. helena dan $P$. aristolochiae memiliki kesamaan antara keduanya, yaitu diawali dengan larva yang berhenti makan, kemudian mencari tempat yang cocok, memendekkan tubuh, membuat benang, menggantung dan terbentuk pupa. Pembuatan benang $T$. helena dan $P$. aristolochiae terjadi pada malam hari. Rata-rata lama pupasi $T$. helena dan $P$. aristolochiae berbeda nyata $(\rho<0,03)$, rata- rata pupasi $T$. helena 4,80 jam lebih lama dibandingkan $P$. aristolochiae. Hasil analisis korelasi antara panjang benang dan berat pupa menunjukkan adanya korelasi yang positif pada kedua spesies tersebut.

\section{DAFTAR PUSTAKA}

Barua, K. K. dan Slowik, J. 2007. Study on The Biology and Consumption Potential of Common Rose Pachliopta aristolochiae aristolochiae F (Lepidoptera: Papilionidae) on Aristolochia tagala. Polish Journal of Entomology. Vol. 76: 341-352.

Bashar, Maksudul, A. dan Humayun, R.K. 2014. Biology Of Common Rose Butterfly, Pachliopta Aristolochiae Fabricius (Lepidoptera: Papilionidae) On The Host Plant, Aristolochia Indica L. (Aristolochiaceae). Journal Biology Science.23 (2): 109-117.

Chin, W. Y. 2014. Plant fact sheet ; Aristolochia tagala. Nature Watch Magazine.

http://habitatnews.nus.edu.sg/pub/nat urewatch/text/a101c.htm. diakses 23 November 2015.

Guillott, C. 2005. Entomology. 3th ed. Springer, Dordrecht, The Netherlands. 
Irianto, A. 2006. Statistik: Konsep Dasar dan Aplikasi. Kencana. Jakarta.

(IUCN) International Union for Conservation of Nature and Natural Resources. 2015.

http://www.iucnredlist.org/threatened. species.html. Diakses 15 Juni 2016.

Larasati, A. 2015. Studi Beberapa Aspek Bioekologi Kupu-Kupu Troides helena L. (Lepidoptera : Papilionidae) di Area Konservasi Taman KupuKupu Gita Persada, Lampung. [Thesis]. Universitas Lampung. Lampung.

Martinus. 2015. http://gitapersada.weebly.com/papilo nidae.html. Diakses 23 November 2015.

Regina C.E. 2008. Information about Butterflies, Caterpillars \& Plants. http://www.gardenswithwings.com/fac tsinfo/NL2008/a0811ButterflyLifeCycle. html. Diakses 23 November 2015

Salmah, S. Abbas, I. dan Dahelmi. 2002. Kupu-kupu Papilionidae Taman Nasional Kerinci Seblat. KEHATI. Departemen Kehutanan. Taman Nasional Kerinci Seblat. Jakarta.

Smart, P. 1991. The Illustrated Encyclopedia of the Butterflies Word. Salamander Books Limited. London.

Soehartono, T. dan Mardiastuti, A. 2003. Pelaksanaan Konvensi CITES di Indonesia. JICA. Jakarta.

Soekardi, H. 2005. Keanekaragaman Papilionidae di Hutan Gunung Betung, Lampung, Sumatera : Penangkaran serta rekayasa habitat sebagai dasar konservasi. [Disertasi]. ITB. Bandung.

Soekardi, H. 2007. Kupu-kupu di Kampus UNILA. Universitas Lampung Press. Lampung. 